\title{
PROTÓTIPO DE UMA CAMARA DE RADIAÇÃO UV-C PARA DESINFECÇÃO DE OBJETOS
}

\section{PROTOTYPE OF A UV-C RADIATION CHAMBER FOR DISINFECTING OBJECTS}

Gabriel da Silva Boigues, Lucas Ramos Veiga, Rafael Bratifich, João Pucci Neto, Fernando Cardoso Fajoni

Universidade do Oeste Paulista - UNOESTE, Presidente Prudente, SP.

E-mail: g boigues2@hotmail.com

RESUMO - Os hospitais usam lâmpadas germicidas nos comprimentos de onda ultravioleta (UV-C - $254 \mathrm{~nm}$ ) para esterilizar equipamentos, água e o ambiente em salas de cirurgia. As indústrias de alimentos e medicamentos as utilizam para desinfectar vários tipos de produtos, recipientes e embalagens. Atualmente essa tecnologia está sendo utilizada para desinfecção de ambientes, equipamentos médico-hospitalares e equipamentos de proteção de uso comum diante da atual pandemia do COVID-19. Diante das aplicações da UV-C para realizar esterilização de ambientes e objetos este projeto envolve - desenvolvimento de um protótipo utilizando uma plataforma de prototipagem eletrônica de hardware de uma câmara com lâmpadas UV portátil para desinfecção de objetivos. Este protótipo é composto por um módulo de hardware e um módulo de software. No módulo de hardware avaliou-se os componentes necessários para a montagem do sistema físico e quais suas funções básicas, tais como acionamento das lâmpadas e dispositivos de segurança enquanto no módulo de software desenvolveu-se o sistema de temporização, o controle de acionamento e desligamento das lâmpadas, a interface e a segurança do usuário, a exposição à radiação através de um sensor magnético reed switch para verificação do estado da porta.

Palavras-chave: Radiação ultravioleta, câmara ultravioleta, microcontrolador.

ABSTRACT - Hospitals use germicidal lamps at ultraviolet wavelengths (UV-C $254 \mathrm{~nm}$ ) to sterilize equipment, water and the environment in operating rooms. The food and medicine industries use them to disinfect various types of products, containers and packaging. This technology is currently being used to disinfect environments, medical and hospital equipment and protective equipment in common use in the face of the current COVID-19 pandemic. In view of the UV-C applications to perform sterilization of environments and objects, this project involves the development of a prototype using a hardware electronic prototyping platform of a chamber with portable UV lamps for disinfecting objectives. This prototype consists of a hardware module and a software module. In the hardware module, the necessary components for the assembly of the physical system were evaluated, as well as its basic functions, such as the activation of lamps and safety devices, while in the software module, the timing system, the activation and shutdown control were developed. of the lamps, the user interface and security, the exposure to 
radiation through a magnetic reed switch sensor to check the state of the door.

Keywords: Ultraviolet radiation, ultraviolet chamber, microcontroller.

\section{INTRODUÇÃO}

O coronavírus (COVID-19) demonstra-se ser um vírus altamente infeccioso, o que propiciou uma pandemia mundial. Ele promove um processo inflamatório grave em diversos órgãos do corpo, em consequência disso provocou um grande aumento do número de óbitos em todo o mundo durante o ano de 2020 (WATANABE, 2020). As mortes estão associadas à síndrome respiratória aguda grave e o COVID-19 tem promovido uma sobrecarga dos sistemas de saúde aumentando mais sua taxa de mortalidade nos casos graves. Sendo assim a melhor medida é a prevenção, sobretudo, a correta higienização e desinfecção de ambientes, equipamentos de proteção, objetos e roupas. Para realizar a higienização e desinfecção desses elementos utiliza-se, geralmente, germicidas diluídos em meio aquoso, tais como: álcool gel e líquido, soluções de hipoclorito de sódio e outros germicidas solúveis. Todavia, a aplicação destas soluções pode ser prejudicial e ineficientes à certos elementos, por exemplo - a higienização de aparelhos celulares, na qual o álcool pode causar danos ao aparelho e por este motivo, usuários realizam uma limpeza superficial do mesmo evitando regiões como entradas do carregador e fones de ouvido.

Entretanto, pode-se utilizar a radiação ultravioleta curta ou germicida (UVC) para desinfectar o aparelho e outros elementos sensíveis à aplicação de soluções de limpeza.

As ondas ultravioletas curtas (UVC - 100 $\mathrm{nm}$ a $280 \mathrm{~nm}$ ) são utilizadas para eliminar bactérias e tornar vírus inativos sendo empregadas em hospitais através de lâmpadas germicidas nos comprimentos de onda ultravioleta (UVC) de $254 \mathrm{~nm}$ para esterilizar equipamentos, água e o ambiente em salas de cirurgia, nas indústrias de alimentos e medicamentos para desinfectar produtos, recipientes e embalagens (ULTRAVIOLETA, 2020; BAGNATO, 2020). Recentemente essa tecnologia é utilizada para desinfecção de ônibus na China (RAIOS..., 2020) e no Brasil uma empresa de transporte instalou um sistema de radiação UVC no banheiro de sua frota de transporte rodoviário
(MARCOPOLO..., 2020) diante da pandemia do coronavírus.

Assim, diante do potencial que o UVC apresenta para desinfecção de ambientes e objetos, o presente trabalho tem por objetivo desenvolver um protótipo utilizando uma plataforma de prototipagem eletrônica de hardware de uma câmara portátil com lâmpadas UVC para desinfecção de objetivos. Dividiu-se o projeto do protótipo em dois módulos: hardware e software.

O módulo de hardware corresponde a seleção dos componentes para a montagem do sistema físico e a elaboração das funções que o protótipo deve apresentar, tais como acionamento das lâmpadas e funções de segurança enquanto o módulo de software corresponde ao desenvolvimento do sistema de temporização, de controle das lâmpadas, de interface e de segurança do usuário à exposição à radiação. A segurança e proteção ao usuário dáse através de um sensor magnético reed switch que verifica o estado da porta - aberta ou fechada - a fim desligar as lâmpadas e impedir que a radiação irradie fora do interior da câmara expondo o usuário ao UVC. Tal mecanismo faz-se necessário devido a radiação UVC ser perigosa e poucos minutos de exposição podem causar queimaduras a pele e outros problemas conforme dose à qual o usuário for exposto (MAGELA, 2019; GAGLIONI, 2020).

\subsection{Radiação ultravioleta curta ou germicida}

A ação de desinfecção da radiação ultravioleta curta ou germicida (UVC - $100 \mathrm{~nm}$ a $280 \mathrm{~nm}$ ) dá-se pela absorção da UVC pelos ácidos nucléicos RNA e DNA e pelas proteínas. Assim, a radiação UVC promove o rompimento da membrana celular ao ser absorvida pelas proteínas causando a morte da célula enquanto pequenas doses de UVC promovem a alteração nos genes do DNA impedindo os microorganismos de se reproduzir, promovendo sua inativação (ARANTES; LIPOMANN, 2011).

A radiação UVC pode promover a eliminação de micro-organismos com eficácia de até $99,9999 \%$ dependendo da potência da fonte ultravioleta e tempo de exposição (GAGLIONI, 
2020). Dessa forma, esses micro-organismos devem ser expostos a uma dose mínima e necessária para sua eliminação na qual a função dose (D) da radiação UVC é calculada por (PROLAMPSALES, 2020):

$$
D(I, t)=I \times t
$$

na qual I é a intensidade da radiação UV em ] $\mathrm{W} / \mathrm{cm}^{2}$ e $t$ é o tempo de exposição em segundos.

Essa dose mínima é necessária para a desativação de alguns micro-organismos, tais como: fungos, bactérias e vírus são apresentados nas Tabelas 1 a 3 a seguir.

Tabela 1. Dosagem para controle de $99,9 \%$ de organismos a UVC-254 nm

\begin{tabular}{l|r}
\hline \multicolumn{1}{c}{ NOME } & \multicolumn{1}{c}{ DOSE } \\
\hline FUNGO & \multicolumn{1}{c}{ [W.s/cm } \\
\hline Aspergillus flavus & 99,000 \\
Aspergillus glaucus & 88,000 \\
Aspergillus niger & 330,000 \\
Mucor racemosus A & 35,200 \\
Mucor racemosus B & 35,200 \\
Oospora lactis & 11,000 \\
Penicillium digitatum & 88,00 \\
Penicillium expansum & 22,000 \\
Penicillium roqueforti & 26,400 \\
Rhizopus nigricans & 220,000 \\
\hline
\end{tabular}

Fonte: (NATURALTEC, 2020).

Tabela 2. Dosegem para controle de $99,9 \%$ de organismos a UVC- $254 \mathrm{~nm}$

\begin{tabular}{l|r}
\hline \multicolumn{1}{c|}{ NOME } & \multicolumn{1}{c}{ DOSE } \\
\hline \multicolumn{1}{c}{ BACTÉRIA } & [W.s/cm $\mathbf{c}^{\mathbf{2}}$ \\
Bacillus anthracis & 8,700 \\
B. enteritidis & 7,600 \\
$\begin{array}{l}\text { B. Megaterium sp. } \\
\text { (vegatative) }\end{array}$ & 2,500 \\
B. Megaterium sp. & \\
(spores) & 52,000 \\
B. subtilis (vegatative) & 11,000 \\
$\begin{array}{l}\text { B. subtilis(spores) } \\
\text { Escherichia coli }\end{array}$ & 58,000 \\
Mycobacterium & 7,000 \\
tuberculosis & 10,000 \\
Proteus vulgaris & 6,600 \\
Pseudomonas & 10,500 \\
aeruginosa &
\end{tabular}

Fonte: (NATURALTEC, 2020).
Tabela 2. Dosegem para controle de $99,9 \%$ de organismos a UVC-254 nm

\begin{tabular}{l|c|}
\multicolumn{1}{c}{ NOME } & (continuação) \\
\hline \multicolumn{1}{c}{ BACTÉRIA } & DW.s/cm \\
\hline $\begin{array}{l}\text { Pseudomonas } \\
\text { fluorescens }\end{array}$ & 6,600 \\
Salmonella enteritidis & 7,600 \\
$\begin{array}{l}\text { Salmonella paratyphi } \\
\text { Salmonella }\end{array}$ & 6,100 \\
typhimurium & 15,200 \\
Salmonella typhus & \\
(Typhoid) & 6,000 \\
Sarcina lutea & 26,400 \\
Serratia marcescens & 6,200 \\
Shigella dysenteriae & 4,200 \\
Staphylococcus albus & 5,720 \\
Staphylococcus & 6,600 \\
aureus & \\
Streptococcus & \\
hemolyticus & 5,500 \\
Streptococcus lactase & 8,800 \\
\hline
\end{tabular}

Fonte: (NATURALTEC, 2020).

Tabela 3. Dosegem para controle de $99,9 \%$ de organismos a UVC- $254 \mathrm{~nm}$

\begin{tabular}{l|c}
\hline \multicolumn{1}{c|}{ NOME } & DOSE \\
\hline \multicolumn{1}{c}{ VÍRUS } & [W.s/cm \\
\hline Bacteriophage ( $E$. & 6,600 \\
coli) & 8,000 \\
Hepatitis virus & 6,600 \\
Influenza Virus & 24,000 \\
Rota virus & 440,000 \\
Tobacco mosaic &
\end{tabular}

\section{METODOLOGIA}

O projeto do protótipo da câmara UVC foi divido em dois módulos principais o módulo de hardware e software.

No módulo de hardware avaliou-se os componentes necessários para a montagem do sistema físico e quais as funções básicas a serem implementada no módulo de software.

No módulo de software desenvolveu-se a programação das funções do protótipo e após o desenvolvimento do sistema avaliou-se seu funcionamento em duas etapas: a primeira consistiu em simular o funcionamento das funções através do software Proteus no qual um equivalente dos módulos do protótipo foram desenvolvidos a fim verificar o programa elaborado; e na segunda etapa realizou-se a montagem e construção dos circuitos dos 
elementos físicos e gravou-se a programação na plataforma de prototipagem eletrônica de hardware para avaliar o funcionamento e interação dos componentes físicos do protótipo.

\subsection{Módulo de hardware}

Para o projeto do protótipo selecionou-se como principais elementos os seguintes componentes para sua elaboração:

- 3 lâmpadas tubular T5 UVC (6 W);

- 3 reatores eletrônico $(15 \mathrm{~W})$;

- 1 módulo relé $5 \mathrm{~V}$ de 4 canais;

- 1 display Icd 16x2 com 12C;

- 1 encoder rotativo com botão;

- 1 sensor magnético reed switch magnético;

- 1 plataforma de prototipagem eletrônica de hardware (Arduino Uno);

- 1 carcaça de micro-ondas;

Definido os principais elementos para o desenvolvimento do protótipo propôs-se as funções que a plataforma de prototipagem eletrônica de hardware executaria:

- Acionar e desligar as fontes de radiação UVC através dos módulos relés;

- Controlar o tempo de exposição a ser aplicada aos objetos no interior da câmara;

- Calcular o tempo de exposição das amostras quando se configura uma dose no menu de acesso.

- Verificar o sensor magnético reed switch para realizar $o$ desligamento das fontes de radiação durante a exposição dos objetos caso a porta da câmara seja aberta antes do termino programado da exposição para segurança do usuário.

- Bloquear o acionamento dos relés antes do início do processo caso a porta esteja aberta.

- Controlar o menu de acesso exibido através do display com as opções de configuração de tempo e dose de exposição.

- Ler a seleção dos elementos e configuração dos submenus através do encoder rotativo.

\subsubsection{Acionamento das lâmpadas UVC}

O controle on/off das lâmpadas UVC é realizado através do módulo relé de 4 canais exibido nas Figuras 1 e 2.
Figura 1. Módulo Relé

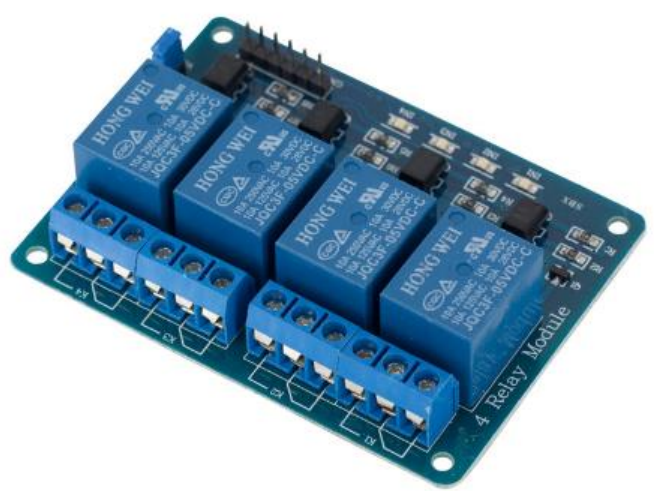

Fonte: (FILIPEFLOP, 2020a).

Figura 2. Exemplo das portas de um módulo relé de 2 canais.

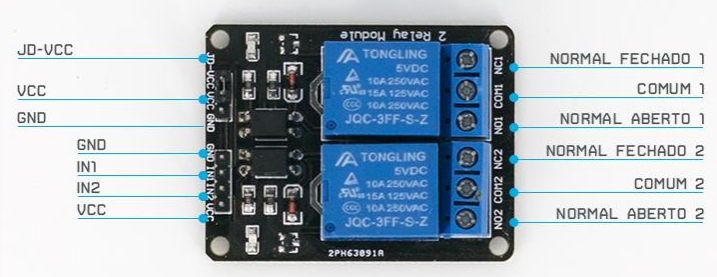

Fonte: (FILIPEFLOP, 2020b).

As especificações do módulo utilizado são (FILIPIFLOP, 2020a):

- Tensão de operação: 5VDC (VCC e GND)

- Tensão de sinal: 5VCD

- Corrente típica de operação: 15-20mA

- Cada relé possui 3 terminais proporcionando 1 contato NA, 1 NF e o Comum.

- $O$ contato do relé permite tensão de até 30 VDC a $10 \mathrm{~A}$ ou $250 \mathrm{VAC}$ a $10 \mathrm{~A}$.

- Tempo de resposta: 5-10 ms

Para a montagem do circuito de acionamento das lâmpadas UVC conectou-se a fase da rede ao comum do módulo relé e a alimentação do reator eletrônico ao circuito NA enquanto o retorno dos reatores foi conectado ao neutro da rede para uma rede de $127 \mathrm{~V}$.

O funcionamento do módulo dá-se por variação no sinal de entrada dos pinos que representam cada canal. Dessa forma, quando os pinos dos canais estão configurados em estado alto (5V) não ocorrer o chaveamento do relé e quando o processo de exposição é acionado os pinos são configurados em estado baixo $(0 \mathrm{~V})$ fechando o circuito de alimentação das lâmpadas. 


\subsubsection{Controle dos menus e acionamentos}

Para acessar os menus e configurar os tempos de exposição e a dose do processo utilizou-se um encoder rotativo com botão como exibido na Figura 3. O encoder mede o movimento rotacional de um eixo e os converte em impulsos elétricos de onda quadrada gerando uma quantidade de impulsos por volta, para o modelo utilizado KY-040 são 20 pulsos por resolução.

Figura 3. Encoder rotativo com botão.

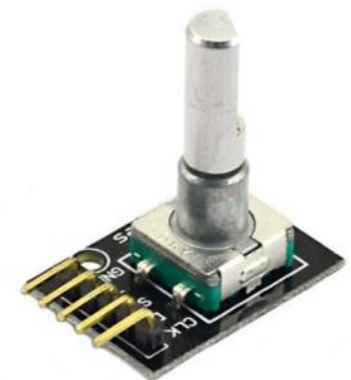

Fonte: (FILIPEFLOP, 2020c).

As especificações do encoder utilizado são (FILIPIFLOP, 2020c):

- Modelo: Keyes KY-040

- Resolução: 20 pulsos por revolução

- Tensão de operação: $5 \mathrm{~V}$

- Corrente max: $10 \mathrm{~mA}$

- Rotação contínua (sem limite)

Pinagem:

- CLK: Pulso do clock. Tem resistor pullup de $10 \mathrm{~K}$ com VCC

- DT: Pulso de direção. Tem resistor pullup de $10 \mathrm{~K}$ com VCC

- SW: Conecta pino ao GND quando eixo pressionado

- +: VCC

- GND: GND

Dessa maneira, quando o encoder é girado para a direita é realizado o acesso dos itens do menu a direita e o incremento do tempo e da dose nos submenus.

Quando o encoder é girado para a esquerda é realizado o acesso dos itens do menu a esquerda e o decremento do tempo e da dose nos submenus.

Para acessar os submenus e iniciar os processos utiliza-se o botão do encoder para confirmar a operação.

\subsubsection{Sistema de segurança}

O sistema de segurança a fim de prevenir a exposição do usuário a radiação UVC do interior da câmera foi implementado através de um sensor reed switch magnético como exibido na Figura 4.

Figura 4. Sensor reed switch magnético.

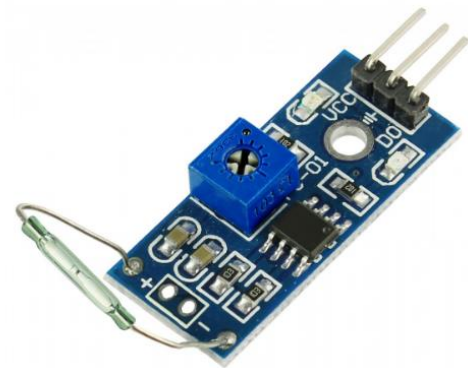

Fonte: (USINAINFO, 2020).

O sensor é posicionado na carcaça do forno micro-ondas junto a lateral da fechadura da porta e um imã de neodímio é instalado na lateral da porta.

O sensor é composto por duas barras metálicas encapsuladas em um invólucro resistente, sem a presença do campo magnético seu estado é normalmente aberto, e o módulo do sensor magnético envia um sinal de estado alto (5V) para a plataforma de prototipagem eletrônica de hardware. Quando ocorre a aproximação de um campo magnético, ou seja, o fechamento da porta os polos encapsulados vão se aproximar e fecham o circuito do sensor e o módulo do sensor magnético envia um sinal de estado baixo $(0 \mathrm{~V})$ para a plataforma permitindo verificar que a porta está fechada.

Dessa forma, o módulo relé somente aciona as lâmpadas UVC se o sinal do sensor está em estado baixo - porta da câmara fechada - e se o sinal do sensor mudar de estado durante o processo de exposição da amostra uma interrupção desativa os relés e reinicia o processo de configuração.

\subsection{Módulo de software}

Para o desenvolvimento das funções do protótipo elaborou-se o seguinte fluxograma do processo de funcionamento apresentado na Figura 5.

A interrupção a ser implementada baseia-se na mudança de borda de estado baixo para alto do sensor reed switch magnético.

A partir do fluxograma desenvolveu-se o programa através da IDE do Arduino que possui uma linguagem própria baseada na linguagem $\mathrm{Ce}$ $\mathrm{C}++$. 
Figura 5. Fluxograma de funcionamento do protótipo.
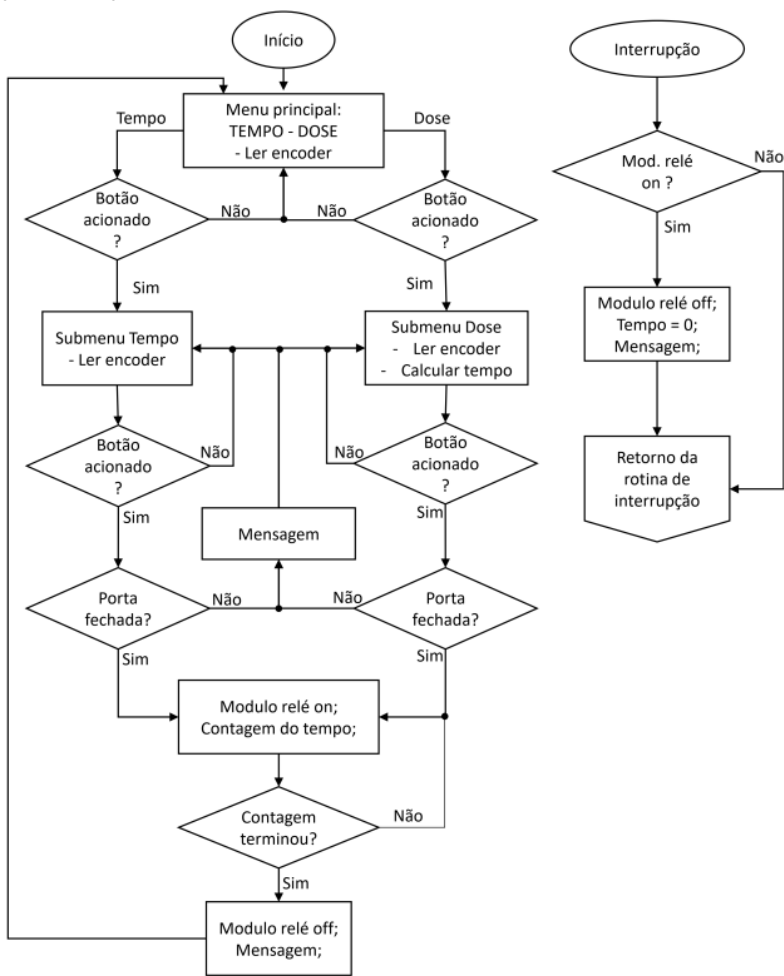

Fonte: (Autores, 2020).

\subsection{Simulação do funcionamento do programa}

Utilizando-se o software Proteus v. 8.7 desenvolveu-se um circuito equivalente ao protótipo da proposta para realizar testes no programa elaborado no IDE. O circuito equivalente é apresentado na Figura 6.

No software simulou-se o funcionamento dos menus e submenus no display, do encoder e do sensor reed switch de segurança.

Figura 6. Circuito elaborado no Proteus para testes do programa elaborado.
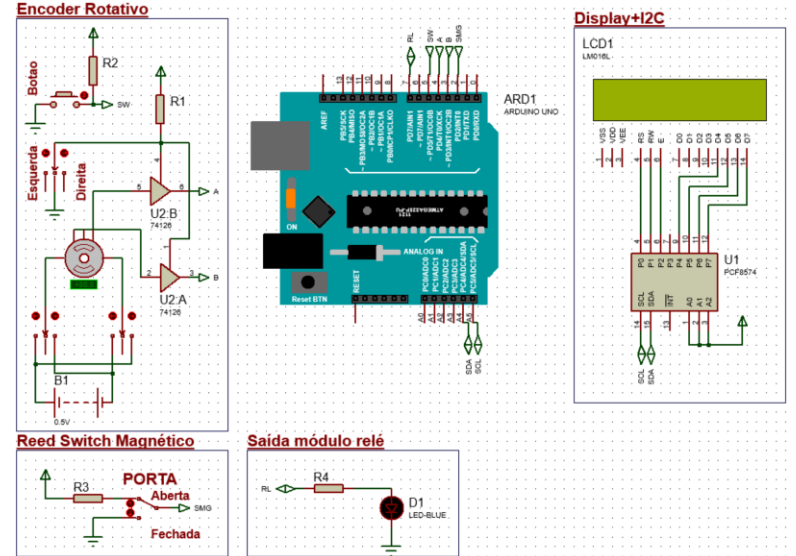

Fonte: (Autores, 2020).

\subsection{Pré-montagem da câmara UVC}

Após a simulação do programa no software Proteus conectou-se os elementos do sistema a uma protoboard para realizar os testes de funcionamento nos elementos físicos antes da montagem final do protótipo.

Inicialmente, montou-se a plataforma de prototipagem eletrônica de hardware, o sensor, o encoder e o módulo relé para os testes iniciais de funcionamento desses elementos. Na Figura 7 são apresentadas as conexões entre esses dispositivos para os testes iniciais.

Figura 7. Sistema inicial para testes.

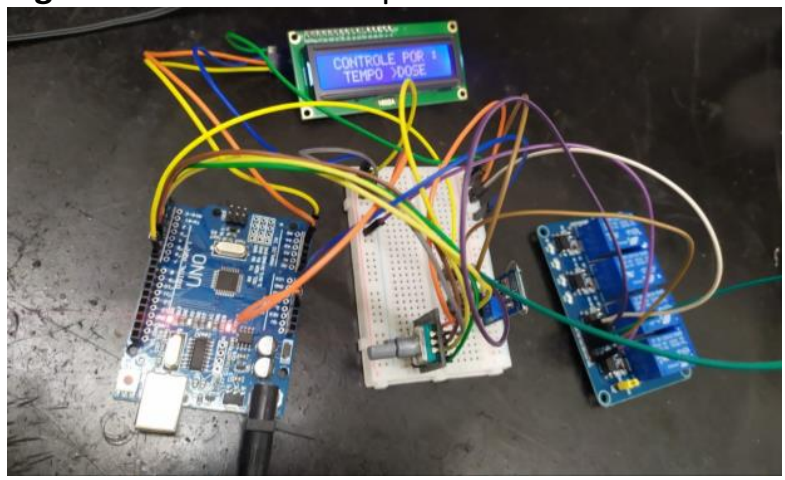

Fonte: (Autores, 2020).

Após a verificação do funcionamento iniciouse a montagem da câmara de UVC como apresentado na Figura 8.

Figura 8. Montagem do sistema de radiação na carcaça do micro-ondas.

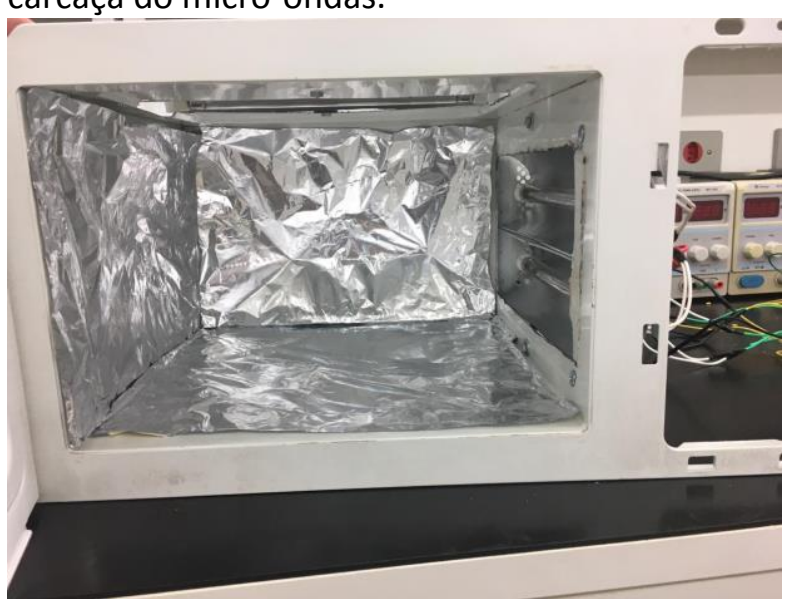

Fonte: (Autores, 2020).

A montagem inicial da câmara possibilitou teste de acionamento das lâmpadas UVC com segurança. Assim, utilizando a pré-montagem dos circuitos do teste inicial conectou-se os reatores eletrônicos aos canais do módulo relé para realizar os testes de acionamento do circuito de radiação UVC como apresentado nas Figuras 9 e 10. 
Figura 9. Montagem do sistema de radiação com o sistema de controle para testes de validação.

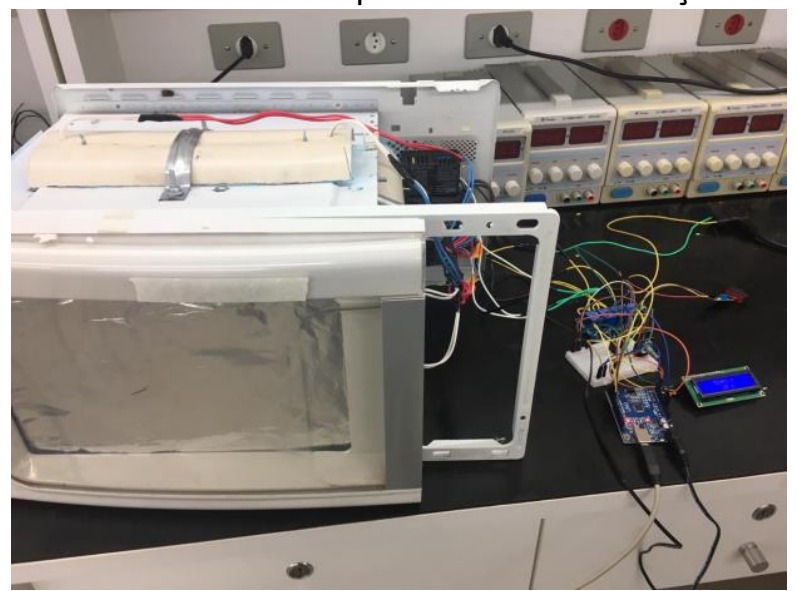

Fonte: (Autores, 2020).

Figura 10. Detalhe da conexão dos elementos.

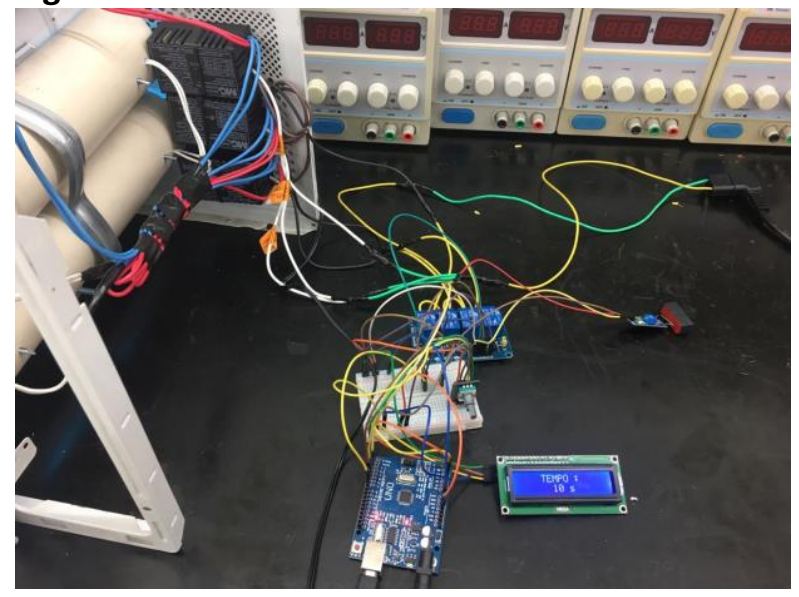

Fonte: (Autores, 2020).

\section{RESULTADOS E DISCUSSÃO}

Inicialmente, realizou-se testes utilizando-se o software Proteus v. 8.7 e após a validação do programa na simulação realizou-se novos testes com a plataforma de prototipagem eletrônica de hardware e seus módulos conectados.

3.1 Simulação das funções e do sistema de segurança

No simulador do software Proteus verificou-se o funcionamento do encoder e dos menus e mensagens de aviso. O sistema de menus elaborado é apresentado nas Figuras 11 a 16.
Figura 11. Detalhe do menu principal simulado no Proteus.

Fonte: (Autores, 2020).

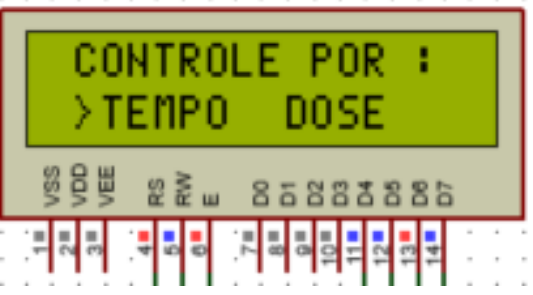

Figura 12. Detalhe do submenu de tempo simulado no Proteus..

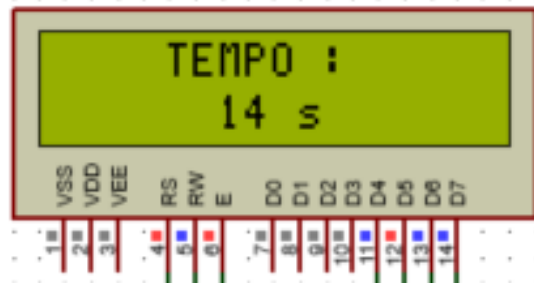

Fonte: (Autores, 2020).

Figura 13. Detalhe do submenu de dose simulado no Proteus.

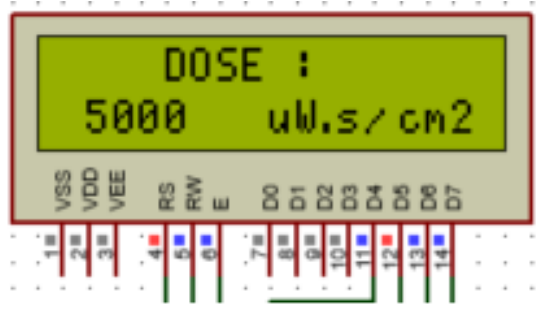

Fonte: (Autores, 2020).

Figura 14. Mensagem de alerta antes do início do processo caso a porta esteja aberta.

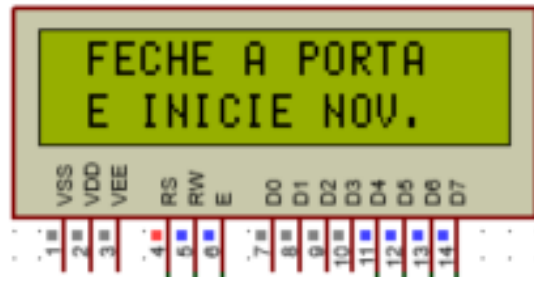

Fonte: (Autores, 2020).

Figura 15. Mensagem de alerta gerada pela interrupção caso a porta seja aberta antes do fim do processo.

Fonte: (Autores, 2020).

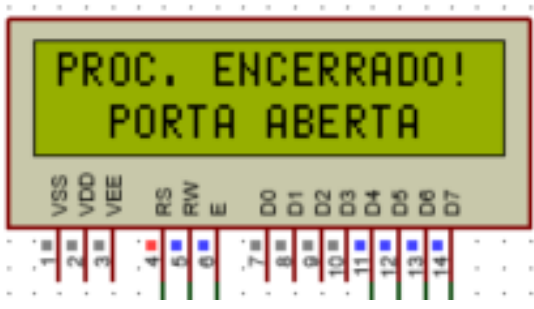


Figura 16. Mensagem de conclusão do processo após terminar o tempo de exposição.

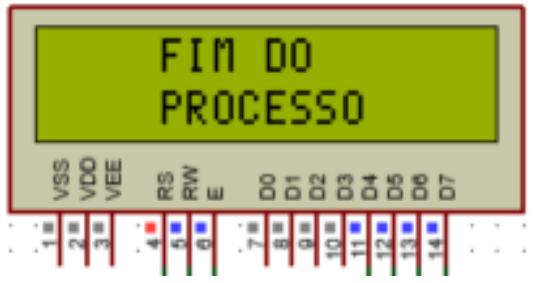

Fonte: (Autores, 2020).

Após validar o encoder, os menus e as mensagens, verificou-se o funcionamento do sensor reed switch magnético e da interrupção. A chave conectada ao GND - porta fechada permite o aciona do led representando o comando de acionamento para o módulo relé como apresentado na Figura 17. Enquanto a chave conectada ao VCC - porta aberta - inibe a ativação do módulo relé e apresenta a mensagem presente na Figura 14. Se a chave for alterada durante o processo de exposição o módulo relé é desativado e a mensagem presente na Figura 15 é exibido.

Figura 17. Validação do sensor de segurança - led azul é acesso enquanto o switch representando os sinais do sensor está no GND durante exposição.

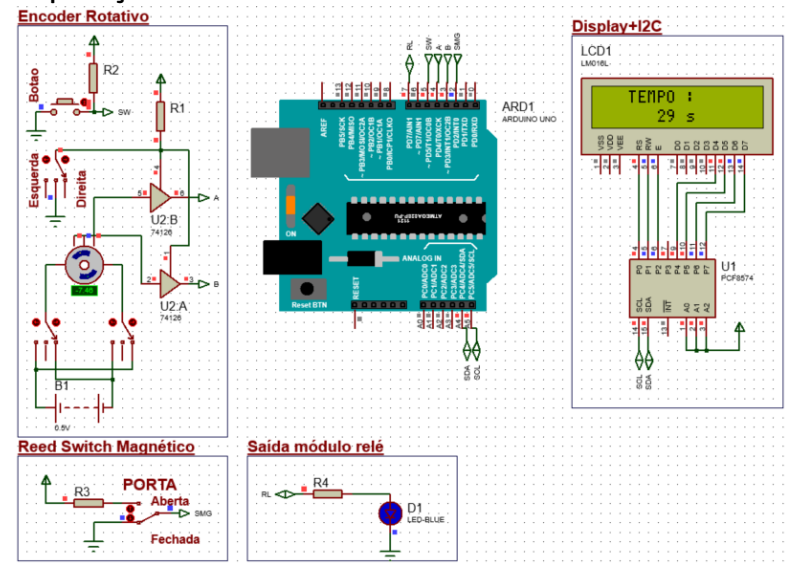

Fonte: (Autores, 2020).

3.2 Teste das funções, do sistema de segurança e do acionamento das lâmpadas.

Após a simulação das funções no Proteus programou-se a plataforma de prototipagem eletrônica de hardware e novamente verificou-se o funcionamento do encoder e dos menus e mensagens de aviso como é apresentado nas Figuras $18-22$.
Figura 18. Menu principal no LCD.

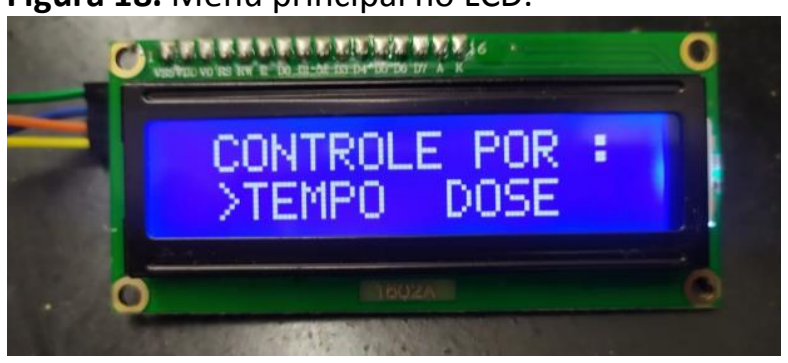

Fonte: (Autores, 2020).

Figura 19. Submenu de tempo no LCD.

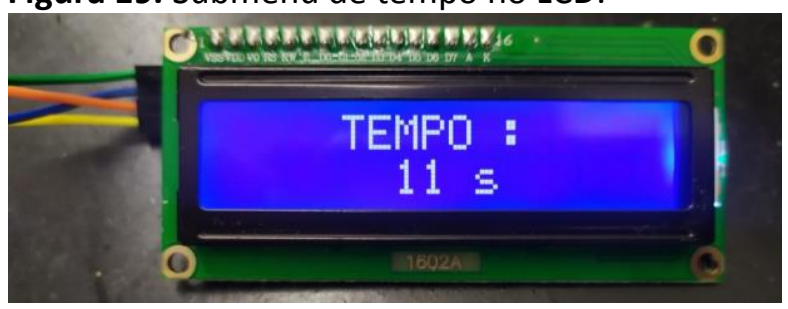

Fonte: (Autores, 2020).

Figura 20. Submenu de dose no LCD

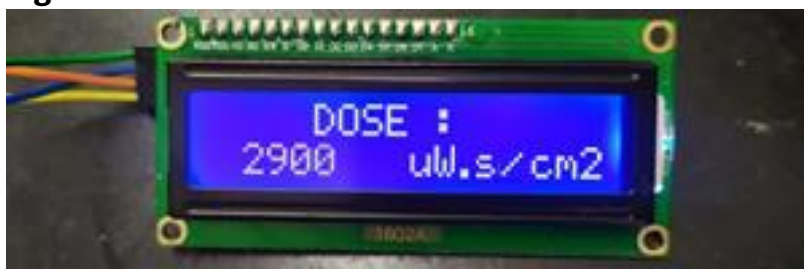

Fonte: (Autores, 2020).

Figura 21. Mensagem de alerta antes do início do processo caso a porta esteja aberta.

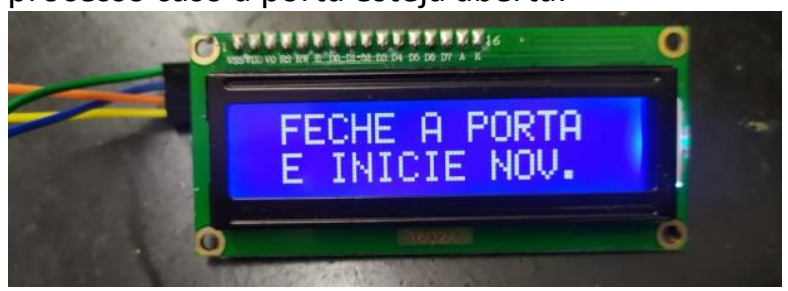

Fonte: (Autores, 2020).

Figura 22. Mensagem de alerta gerada pela interrupção caso a porta seja aberta antes do fim do processo.

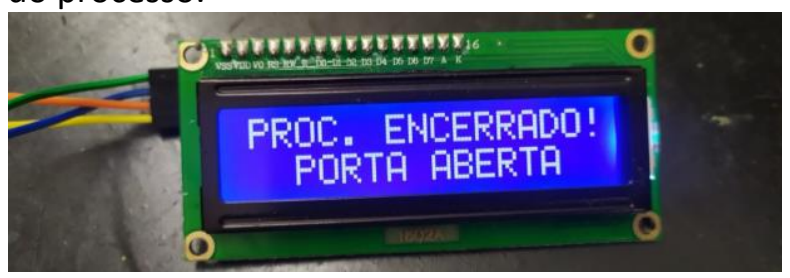

Fonte: (Autores, 2020).

Validando o encoder, os menus e as mensagens, verificou-se o funcionamento do sensor reed switch magnético e da interrupção.

Para os testes com o sensor utilizou-se um imã que foi aproximado e retirado do sensor 
e avaliou-se o funcionamento do módulo relé ao iniciar o processo de exposição.

Nas Figuras 23 e 24 são apresentados o acionamento do módulo relé, representado pelos leds vermelhos acesos na placa, enquanto o bloco do imã está sobre o sensor durante o processo de exposição.

Figura 23. Módulo relé ativo enquanto o imã está sobre o sensor reed switch magnético durante o processo de exposição.

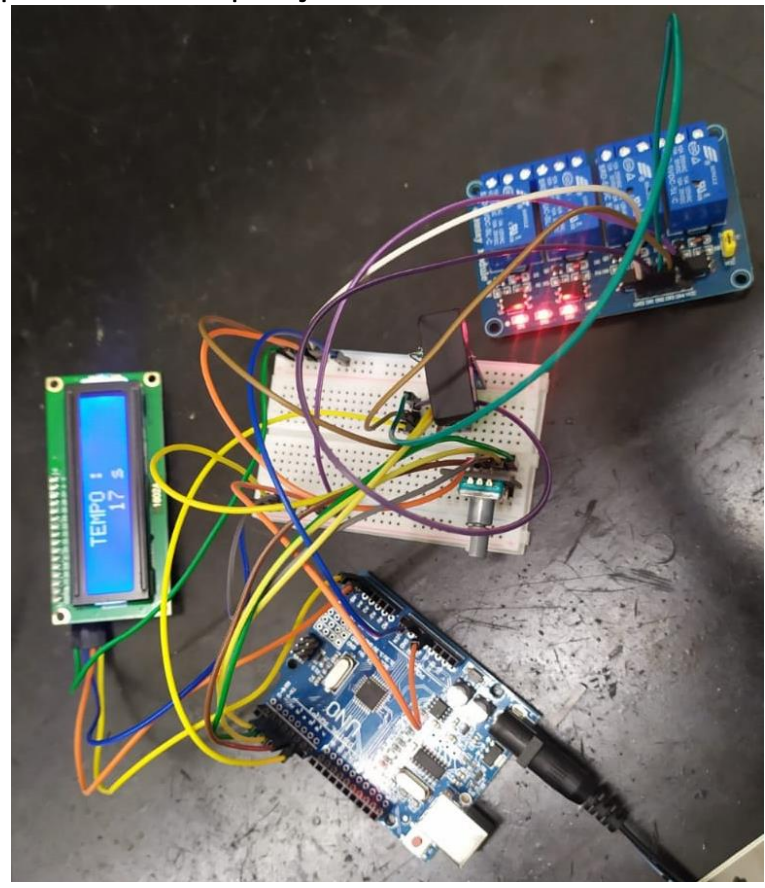

Fonte: (Autores, 2020).

Figura 24. Detalhe do imã sobre o sensor e os canais ativos - led vermelho acesso - no módulo relé.

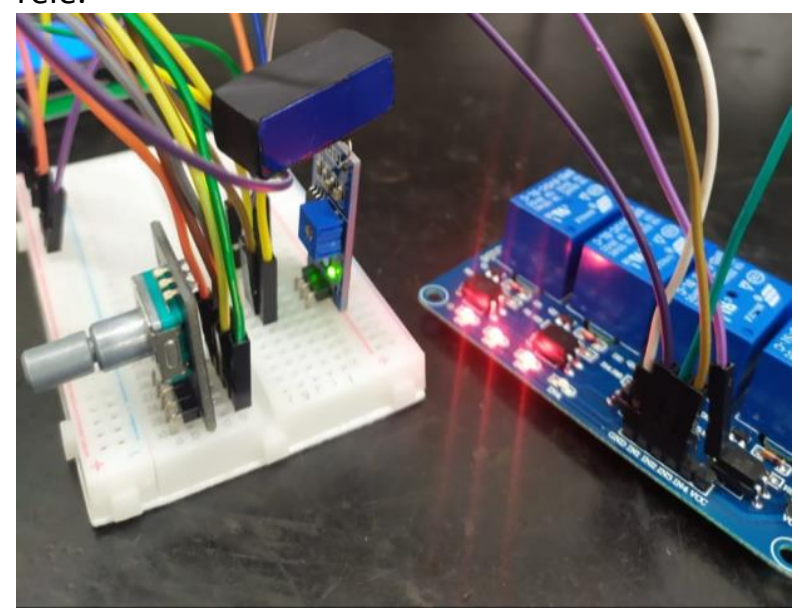

Fonte: (Autores, 2020).

Após os testes iniciais conectou-se os reatores ao módulo relé para teste de acionamento das lâmpadas como é apresentado na Figura 25.
Figura 25. Teste do acionamento das lâmpadas através do módulo relé.

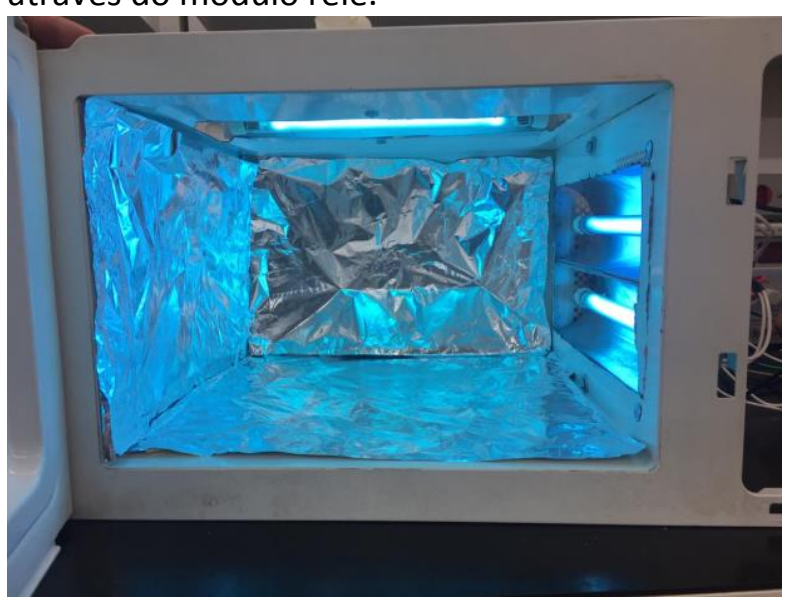

Fonte: (Autores, 2020).

Utilizando-se os menus para programar tempo e dose foi possível realizar o controle do acionamento das lâmpadas UVC como proposto e com isso controlar o tempo de exposição da amostra a partir do sistema. Segundo a PHILIPS... (2020) a lâmpada tubular TUV 6W-G5, posicionada a uma distância de $1 \mathrm{~m}$ do alvo, apresenta irradiância de $15 \mathrm{QW} / \mathrm{cm}^{2}$. Assim, utilizando-se aproximações radiométrica pode-se estimar através da lei do inverso do quadrado a irradiância da lâmpada UVC, dada por (PASCOAL, 2016):

$$
\begin{gathered}
E_{1} \times d_{1}^{2}=E_{2} \times d_{2}^{2} \\
E_{1}=E_{2} \times \frac{d_{2}^{2}}{d_{1}^{2}}
\end{gathered}
$$

na qual $E_{j}$ representa a irradiância e $d_{j}$ a distância entre a fonte de intensidade I e uma área $A$ como apresentada na Figura 26.

Figura 26. Ilustração da lei do inverso do quadradro.

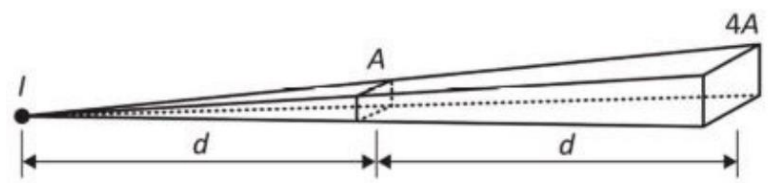

Fonte: (PASCOAL, 2016).

Considerando as dimensões da câmara de $30 \mathrm{~cm}$ de largura e $20 \mathrm{~cm}$ de altura, estima-se, para uma lâmpada em relação a parede oposta a sua instalação:

$$
\begin{gathered}
E_{x_{c m}}=E_{1_{m}} \times \frac{d_{1_{m}}^{2}}{d_{x_{c m}}^{2}} \\
E_{30_{c m}}=15 \cdot\left(\frac{1}{0,3}\right)^{2}=166,67 \frac{\mu W}{\mathrm{~cm}^{2}}
\end{gathered}
$$




$$
E_{20_{c m}}=15 \cdot\left(\frac{1}{0,2}\right)^{2}=375,00 \frac{\mu W}{\mathrm{~cm}^{2}}
$$

e como há duas lâmpadas na lateral da câmara e uma na tampa superior estima-se uma intensidade na câmara:

$$
E_{T}=2 \cdot E_{30_{c m}}+E_{20_{c m}}=708,34 \frac{\mu W}{\mathrm{~cm}^{2}}
$$

\section{CONCLUSÕES}

No presente projeto apresentou-se o desenvolvimento de um protótipo de uma câmara de desinfeção de objetos controlada por uma plataforma de prototipagem de hardware a fim de controlado o tempo ou a dose de exposição dos objetos a serem esterilizados utilizando-se radiação UVC.

O funcionamento do protótipo foi validado através de simulação no software Proteus e por testes físicos na plataforma de prototipagem de hardware nos quais verificou-se o correto funcionamento do sistema proposto.

Estimasse que a câmara apresente uma irradiância de 708,34 [W/ $/ \mathrm{cm}^{2}$. Dessa forma, as próximas etapas do projeto consistem em finalizar a montagem dos circuitos e da câmara e realizar testes de validação do sistema de desinfecção.

\section{AGRADECIMENTOS}

Ao departamento de Engenharia Elétrica da Universidade do Oeste Paulista - Campus II, pelo apoio no desenvolvimento deste projeto.

\section{REFERÊNCIAS}

ARANTES, F. A.; LIPPMANN, F. C. Desinfecção de água por lâmpadas ultravioleta a partir de energia solar fotovoltaica sem utilização de baterias. 2011. Trabalho de Conclusão de Curso. (Engenharia Industrial Elétrica Ênfase em Eletrotécnica) -Universidade Tecnológica Federal do Paraná, Curitiba, 2011. Disponível em: http://repositorio.roca.utfpr.edu.br/jspui/bitstre am/1/320/1/CT COELE 201122 20.pdf. Acesso em: 09 de set. 2011.

BAGNATO, V. O poder da luz ultravioleta (UV-C) no combate à COVID-19. COVID-19 - IFSC, São Carlos, 19 de abr. 2020. Seção: Notícias. Disponível em: https://www2.ifsc.usp.br/portalifsc/o-poder-da-luz-ultravioleta-uv-c-nocombate-a-covid-19/. Acesso em: 01 maio 2020.

CHAVES, T. F. H. Desenvolvimento de um protótipo de luz ultravioleta para tratamento de alimentos. 2018. . Trabalho de Conclusão de Curso. (Engenharia de Alimentos) - Universidade Tecnológica Federal do Paraná, Campo Mourão, 2018. Disponível em:

http://repositorio.roca.utfpr.edu.br/jspui/bitstre am/1/10454/1/luzultravioletatratamentoaliment os.pdf. Acesso em: 01 . maio 2020.

FILIPIFLOP. Módulo Relé 5V 4 Canais. Disponível em:

https://www.filipeflop.com/produto/módulorele-5v-4-canais/. Acesso em: 24 de ago. de 2020a.

FILIPIFLOP. Controlando lâmpadas com Módulo Relé Arduino. Disponível em: https://www.filipeflop.com/blog/controlemódulo-rele-arduino/. Acesso em: 24 ago. 2020b.

FILIPIFLOP. Encoder Decoder KY-040 Rotacional. Disponível em:

https://www.filipeflop.com/produto/encoderdecoder-ky-040-rotacional/. Acesso em: 24 ago. 2020c.

GAGLIONI, C. Quais os riscos de usar a luz ultravioleta contra o coronavírus. Nexo Jornal, Seção Expresso, 07 de jul. 2020. Disponível em: https://www.nexojornal.com.br/expresso/2020/ 07/07/Quais-os-riscos-de-usar-a-luz-ultravioletacontra-o-coronav\%C3\%ADrus. Acesso em: 9 set. 2020.

\section{MAGELA, P. Entenda tudo sobre a Lâmpada UV}

(Ultravioleta). VR Brasil, 20 de ago. 2019.

Disponível em:

https://blog.vrbrasil.com/lampada-uv-ultravioleta-germicida/. Acesso em: 9 set. 2020.

MARCOPOLO cria sistema que desinfeta sanitário de ônibus com luz ultravioleta. Estadão, Seção Estradão, jun. 2020. Disponível em: https://estradao.estadao.com.br/onibus/marcop olo-sistema-desinfecao-sanitarios/. Acesso em: 25 ago 2020.

NATURALTEC - Desinfecção Ultravioleta | (UV). Disponível em: https://www.naturaltec.com.br/ultravioletateoria/. Acesso em: 09 set. 2020.

PASCOAL, D. G. Desenvolvimento e Validação do Sistema de lluminação de Luz Ultravioleta (UV e VUV) da Infraestrutura de Simulação de 
Deterioração de Coberturas de Satélites. 2016. Dissertação (Mestrado em Engenharia Física) Universidade de Lisboa, Lisboa, 2016. Disponível em: https://repositorio.ul.pt/bitstream/10451/25206 /1/ulfc120604_tm_Diana_Pascoal.pdf. Acesso em: 09 de set. 2020.

PHILIPS TUV low pressure mercury lamps and drivers. Disponível em: http://www.mcphybec.co.jp/en/products/img/lamp/TUV\%20Tech nical\%20Data.pdf. Acesso em: 09 set. 2020.

PROLAMPSALES: How to Calculate UV-C Dose on a Surface. Disponível em:

https://www.prolampsales.com/blogs/specialtyarchitectural-lighting/how-to-calculate-uv-cdose-on-a-surface. Acesso em: 09 set. 2020.

RAIOS ultravioleta estão sendo usados para desinfectar os ônibus na China. Correio Brasiliense, Seção Mundo, Mar. 2020. Disponível em:

https://www.correiobraziliense.com.br/app/notic $\mathrm{ia} /$ mundo/2020/03/13/interna_mundo,834070/r aios-ultravioleta-estao-sendo-usados-paradesinfetar-os-onibus-na-chi.shtml. Acesso em: 25 ago. 2020.

SOARES, H. Dispositivo com luz ultravioleta poderá descontaminar alimentos em casa. Disponível em:

https://foodsafetybrazil.org/dispositivo-com-luzultravioleta-podera-descontaminar-alimentosem-

casa/\#: : :text=Enquanto\%200\%20\%E2\%80\%9Cfor no\%E2\%80\%9D\%20de\%20luz,em\%20imers\%C3\% A3o\%20por\%2015\%20minutos./. Acesso em: 01 maio 2020.

TINÔCO, J. D. Desinfecção por radiação ultravioleta: estudo do desempenho do processo e avaliação econômica. 2011. Tese (Doutorado) - Escola de Engenharia de São Carlos, Universidade de São Paulo, São Carlos, 2011. Disponível em:

https://www.teses.usp.br/teses/disponiveis/18/1 8138/tde-04052012-

093819/publico/JulianaTinoco.pdf. Acesso em: 01 maio 2020.

ULTRAVIOLETA. Invivo-Fiocruz. Disponível em: http://www.invivo.fiocruz.br/cgi/cgilua.exe/sys/s tart.htm?infoid=125\&sid=9. Acesso em: 01 maio 2020.

\section{USINAINFO. Módulo Sensor Magnético para}

Arduino. Disponível em:

https://www.usinainfo.com.br/outros-sensoresarduino/módulo-sensor-magnetico-para-arduino3104.html. Acesso em: 24 ago. 2020.

VAZ, F. A. S.; OLIVEIRA, M. A. L.; QUEIROZ, M. P. G.; RIBEIRO, S. J. L. Construção de câmara de luz ultravioleta para fotopolimerização de fases estacionárias monolíticas. Química Nova, São Paulo, v. 31, n. 8, p. 2156-2158, 2008. Disponível em:

http://www.scielo.br/scielo.php?script=sci_arttex $\mathrm{t} \& \mathrm{pid}=\mathrm{S} 0100$

40422008000800041\&lng=en\&nrm=iso. Acesso em: 01 maio 2020.

https://doi.org/10.1590/S0100$\underline{40422008000800041}$

VIDALE, G. Coronavírus: Radiação ultravioleta é nova arma para desinfecção. Revista Veja, 24 de abr. 2020. Disponível em:

https://veja.abril.com.br/saude/coronavirusradiacao-e-nova-arma-para-desinfeccao/. Acesso em: 01 maio 2020.

WATANABE, P. 'Tempestade inflamatória' ajuda a explicar mortes pela Covid-19. Folha de São Paulo, São Paulo, 05 de abr. de 2020. Disponível em:

https://www1.folha.uol.com.br/equilibrioesaude /2020/04/tempestade-inflamatoria-ajuda-aexplicar-mortes-pela-covid-19.shtml. Acesso em: 01 maio 2020. 